\title{
Asset Management Business Model for Design, Realization, and Maintenance of Fibre Reinforced Polymer Bridges
}

\author{
Rizal Sebastian \\ TNO Technical Sciences, Expertise Centre of Building and Civil Engineering, Van Mourik Broekmanweg 6, \\ 2628 XE Delft, The Netherlands \\ Correspondence should be addressed to Rizal Sebastian; rizal.sebastian@tno.nl
}

Received 22 January 2013; Revised 9 March 2013; Accepted 17 March 2013

Academic Editor: Issam Srour

Copyright (C) 2013 Rizal Sebastian. This is an open access article distributed under the Creative Commons Attribution License, which permits unrestricted use, distribution, and reproduction in any medium, provided the original work is properly cited.

This paper particularly addresses the market implementation of Fibre Reinforced Polymer (FRP) for bridges. It presents the concept of demand and supply chain innovation as being investigated within two ongoing European collaborative research projects (FP7) titled Trans-IND and PANTURA. FRP has emerged as a real alternative structural material based on various sustainability considerations, among others the reduced life-cycle cost due to less maintenance needs, longer lifetime, and easiness to repair, replace, or recycle the components. The Trans-IND research project aims to develop and demonstrate new industrialized processes to use FRP for civil infrastructure projects at a large scale. In order to be cost effective, a new value-chain strategy for the design, realization, and maintenance of FRP bridges is required to replace the fragmented supply chain and the one-off approach to a construction project. This paper focuses on the development of new business models based on asset management strategy, which covers the entire demand and supply chains. Research on new business models is supported by the insight into the market and regulatory frameworks in different EU countries. This is based on field surveys across the EU that have been carried out as a part of the Trans-IND and PANTURA collaborative research projects.

\section{Introduction}

Fibre Reinforced Polymer (FRP) has emerged as a real alternative structural material based on various sustainability considerations, among others the reduced life-cycle cost due to less maintenance needs, longer lifetime, and easiness to repair, replace, or recycle the components. Up till now, the application of FRP-in civil infrastructure projects is limited. Broad implementation of an industrialized approach to design, manufacture, construct, and use of FRP based civil infrastructure depends on the availability of an innovative business model that is able to assure the demand and supply chain integration throughout the life cycle of the product.

Studies in two European collaborative research projects Trans-IND and PANTURA $[1,2]$ show that when it comes to procurement strategy for infrastructure projects, the client, which is in most projects a public authority, often awards the contract to the lowest price contractor. The contractor carries out the work to fulfill the detailed design and specifications provided by the client at the minimum level to keep the low cost. This traditional attitude to procurement and tender procedure constitutes one of the most important barriers to overcome to promote the use of innovative construction materials and techniques, such as FRP for bridges.

At the European level, attempts towards more innovative procurement have been made. The EU Directive 2004/18/EC that describes the procedures for public works procurement specifies that contracts can be awarded either to the lowest price or to the most economically advantageous tender or MEAT $[2,5,6]$. The award of contracts should in both cases comply with the principles of equal treatment, nondiscrimination, and transparency. However, many players in the European construction sector still perceive significant obstacles to the implementation of alternative procurement strategies based on other criteria than the lowest price. First, it may complicate the justification of the decision by the client and hence lead to higher risks for appeal. This may cause delays or additional costs in a project. Second, it may become 
more difficult for the client to control during the course of the project that the level of performance on which the procurement decision was based is actually fulfilled. Third, it has been very little used before and requires a new way of thinking. Guidelines defining how to assess the tenders would need to be defined. This is seen as a progressive and iterative process that would need to be refined by experience.

This paper reports the preliminary outcome of the research carried out within the EU FP7 collaboratives project Trans-IND and PANTURA. One of the objectives of these projects is to develop and demonstrate new industrialized processes to use FRP for civil infrastructure projects at a large scale. In order to be cost effective, a new valuechain strategy for the design, realization, and maintenance of FRP bridges is required to replace the fragmented supply chain and the one-off approach to a construction project. Therefore, this paper proposes a business model that will transform a resource-based and supply-driven construction sector into a sustainable performance-driven sector, which is user-oriented, flexible, creative, innovative, effective, and efficient in the whole life cycle of the civil infrastructures. The transformation is needed both at the demand side as well as at the supply side. The demand side should become performance driven instead of lowest-price driven. The supply side should become proactive and capable of taking the initiatives and the responsibilities for integrated product development, delivery, and maintenance.

This paper particularly discusses the concept of asset management, which has recently been introduced and adopted in the civil infrastructure sector. The main drive behind this is the needs of the (public) clients to get more certainty of the long-term maintenance and operational effort and costs of the infrastructure. This is crucial to assure that the infrastructure is available to support transport and mobility. Good planning and anticipation of road blocks or detours, which may increase the travel time, traffic load, and logistics, are important to avoid the negative impact on the economy.

\section{Materials and Methods}

The term "asset management" used in the civil infrastructure sector may address one or more definitions, such as the organizational structure and management of a group of civil infrastructure projects; the cost and benefit analysis of civil infrastructure projects; the integrated contract (e.g., design-build-maintain-operate) to assign the private parties to manage the civil infrastructure projects to a certain period of time; and the maintenance plans in relation to the financial value and economic impact of the civil infrastructures. The British Standards Institution (BSI) has made an attempt to clearly define asset management and to develop the relevant guidelines and specifications known as PAS $55[7,8]$. PAS 55 is Publicly Available Specification for the optimized management of physical assets. It describes what must be done in joined-up planning and delivery, in the integrated management of acquisition/creation operation, maintenance, and disposal/renewal, and in the many generic "enablers" that underpin sustainable, optimized performance.

Ideas of applying asset management in the civil infrastructure sector as well as the development of supporting decision-making instruments are not totally new. Vanier [9] provided a retrospective overview of asset management in the construction industry, as it relates to information technologies and decision-support tools. He identified the extent of the asset management market in North America, addresses the need for decision-support tools for municipaltype organizations, and identifies the challenges for maintenance, repair, and renewal planning faced by asset owners and managers. Halfawy [10] discussed the main challenges for implementing integrated municipal infrastructure management environments and proposes specific solutions to address these challenges. He acknowledged that municipal infrastructure management decision making was inherently an integrated process that requires the assimilation of a multitude of data, processes, and software systems. He proposed solutions that addressed the systematization and coordination of work processes, the development of centralized shared data repositories based on nonproprietary integrated data models, and the organization and integration of distributed software tools into a modular and extensible enterprise-wide software environment.

The urgency to use asset management became clear when there was a policy shift towards a more market-oriented approach. Vrijhoef et al. [3] explained how the construction industry can be transformed from demand-driven to supply-driven. Their market oriented model implied the balance between the roles of public clients and contractors to stimulate innovation in the value chain of the construction industry. Figure 1 illustrates the shift from the traditional business model based on capacity (working effort) supply by the contractors to the efficient process integration based on design-and-build procurement and towards the total product-service market approach.

In the last few years, public governments in many countries have started using innovative supplier selection methodologies that are drawn from the established practices of private sector. The traditional procurement is widely known by the sequential "design-bid-build" process. It is characterized by a contractual separation between design and construction responsibilities. Based on the design and technical specifications, the client organizes a public tender to appoint a contractor. The integrated procurement is commonly identified as the "design-and-build" process, which can include the extended forms of design-buildmaintain (DBM), design-build-finance-maintain (DBFM), and design-build-finance-maintain-operate (DBFMO). In the integrated procurement, the client establishes a contract with a single party (a main contractor or a consortium of designer and contractor), which assumes the full responsibility for both designing and constructing the project. The tender procedure, prior to contracting, is based on the functional program of requirements, instead of the detailed design and technical specifications $([6,11]$, Joint Contract Tribunal, [12]). 


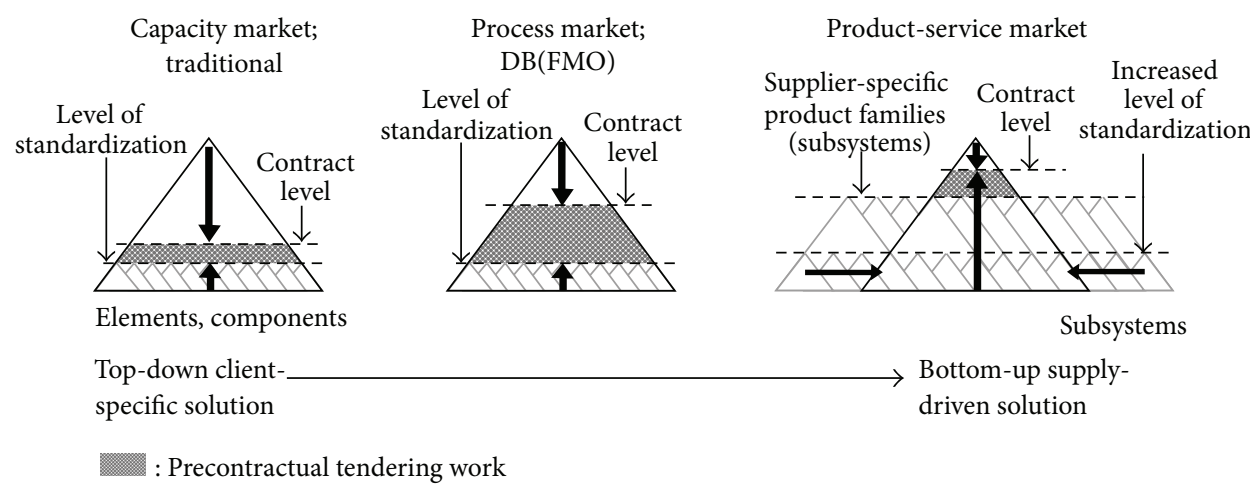

Figure 1: Proposed transition of the construction industry [3].

The need to adopt asset management approach in the civil infrastructure sector is widely recognized [13]. Civil infrastructure concerns are not only due to a shortage of investment, but also to a lack of fundamental knowledge and metrics for describing the valuation, condition, and performance of the whole network or system. The term asset management is borrowed from economics and finance to describe a whole-systems approach to plan, finance, construct, operate, and maintain the civil infrastructures, which would be highly beneficial to the long-term performance of civil engineering assets.

The following sections of this paper discuss the implications of asset management for value-chain integration for both the clients and the construction companies, or in other words the demand and the supply perspectives. The discussions on the new business models are supported by the insight into the market and regulatory frameworks in different EU countries based on field surveys. The reference points and main aspects of the analysis in the following sections of this paper are presented in Table 1 .

This paper refers to the result from a recent survey in the Trans-IND project in order to analyze the practice of performance-based procurement, especially reflecting on asset management for FRP bridges [14]. The main objective of the survey was to collect data for analysis of the current and future scenarios of the road infrastructures' development. It aimed to describe the market, identify target groups, and position the FRP materials and construction techniques for bridges in the most potential market. Once the FRP market strategy was positioned, current and future competitors were identified. The survey also referred to specific studies, such as forecasting the major trends of civil infrastructure development, identify the key factors influencing these trends to and identifying the key drivers and barriers the application of FRP. The data were collected based on project observations (i.e., description of the applied procurement strategies and lessons learned) and in-depth interviews with the responsible actors (i.e., tender managers and project managers) to gather their opinions on FRP-based technologies and the associated procurement models. The survey was conducted in the following countries: The Netherlands (6 samples), Spain (3 samples), Italy (3 samples), Poland (2 samples), and Macedonia (2 samples).

\section{Results and Discussion}

\subsection{Value-Chain Integration from the Client's Perspective}

3.1.1. Concept. In the recent development of procurement procedures, two-stage contracting or tendering contract has emerged [15]. This development is aligned with the policy of public clients to enhance the contractor-led innovation in integrated contract using open-solution specification as a functional program of requirements. The invitation to tender is in some circumstances to be treated as an offer to make a contract which a tenderer accepts when it submits a conforming tender. All tenderers are entitled to know the basis on which tenders will be evaluated and on which a contract-award decision will be made. Tender conditions for a project involving design must include criteria for evaluating that design, as well as criteria for evaluating performance. If an innovation is required, the client must expressly create the right for a tenderer to submit an alternative tender.

By trusting the contractor in finding the innovative solution, the client needs to formulate its functional requirements instead of detailed technical design. The scope must not be too tight so as to restrict innovation but not too wide so as to result in a proposal for a scheme quite different to the one originally tendered for. This means prescribing a required behavior rather than a required solution. This leaves open the possibility for several solutions. Difficulties in the practice of "specifying functionally" are found in the legal implementation of the tender protocols and in fulfilling the condition for unambiguous evaluation of the design proposals. A working method to develop open-solution program of requirements based on systems engineering has recently been introduced in The Netherlands [16].

Houten et al. [17] proposed a model for asset management in the civil infrastructure sector. This model was verified through interviews with experts in asset management and officials in The Netherlands. Different from the assets in private sectors, the assets in the civil infrastructure sector have several unique characteristics. The proposed model was developed in line with the unique characteristics of the infrastructure assets and asset management principles and criteria. The proposed model considered activities at three levels, namely, the strategic, tactical, and operational levels. 
TABLE 1: Main subjects for the analysis of asset management for clients and contractors.

\begin{tabular}{|c|c|c|}
\hline & Clients & Contractors \\
\hline Key stakeholders & $\begin{array}{l}\text { Public clients (i.e., ministries of transport and } \\
\text { infrastructure, regional and local authorities, } \\
\text { semipublic corporations, public-private partnership } \\
\text { corporations, etc.) that own and operate civil } \\
\text { infrastructure objects as a part of local or regional } \\
\text { transport and mobility systems }\end{array}$ & $\begin{array}{l}\text { Industrial companies (i.e., construction firms, } \\
\text { manufacturers, material and component suppliers, } \\
\text { design and technical engineers, inspection and } \\
\text { maintenance specialists, etc.) that develop, } \\
\text { manufacture, install, and maintain the civil } \\
\text { infrastructure objects and their components }\end{array}$ \\
\hline $\begin{array}{l}\text { Main business } \\
\text { agenda }\end{array}$ & $\begin{array}{l}\text { Focus on the end-products as a whole (e.g., bridges, } \\
\text { roads, and tunnels) and their contribution for an } \\
\text { optimal functioning of transport network }\end{array}$ & $\begin{array}{l}\text { Focus on the development and delivery of components } \\
\text { and products with sustainable business cases for the } \\
\text { companies and the market }\end{array}$ \\
\hline $\begin{array}{l}\text { Implications of } \\
\text { asset management }\end{array}$ & $\begin{array}{l}\text { A shift from the ad hoc realization and maintenance of a } \\
\text { particular civil infrastructure object towards a proactive } \\
\text { strategy for the whole transport network, based on } \\
\text { comprehensive monitoring and forecasting knowledge } \\
\text { Performance, especially in terms of the availability and } \\
\text { accessibility of the civil infrastructure (for instance } \\
\text { maximum traffic capacity and minimum disturbance } \\
\text { due to construction and repair work), becomes the } \\
\text { main priority }\end{array}$ & $\begin{array}{l}\text { A civil infrastructure object (e.g., a bridge) is no longer } \\
\text { developed and delivered for a client as a "one-off" } \\
\text { project, but as a "purchase and customize order" that } \\
\text { refers to the serial production process } \\
\text { The products are categorized in standard product } \\
\text { families. A product family is developed based on } \\
\text { parametric design and mass-customizable elements } \\
\text { within a certain range of scale, function, capacity, } \\
\text { modification possibilities, and so forth. Asset } \\
\text { management comprises the most effective and efficient } \\
\text { process throughout the product lifecycle }\end{array}$ \\
\hline $\begin{array}{l}\text { Implications of } \\
\text { value-/supply- } \\
\text { chain } \\
\text { integration }\end{array}$ & $\begin{array}{l}\text { Value-chain integration based on an innovative } \\
\text { collaboration with the industry through an integrated } \\
\text { project delivery strategy using performance-based } \\
\text { procurement }\end{array}$ & $\begin{array}{l}\text { Supply-chain integration by establishing comakerships } \\
\text { or long-term partnerships with industrial partners } \\
\text { within the development and supply-chain of certain } \\
\text { products }\end{array}$ \\
\hline
\end{tabular}

At the strategic level, the policy objectives and available funds are the starting point of the asset management process. The selected solutions are encapsulated in a plan of actions. From the plan of actions, the solutions are developed into projects, which are prioritized based on criteria. The performance of the strategic level is measured to check whether or not the policy objectives are achieved. These projects function as the input to the tactical level. From this planning, budgets will be composed; subsequently, a decision will be made to execute the suggested measure on the basis of a set of decision criteria. Furthermore, schedule of these activities is established. The schedule from the tactical level becomes the input to the operational level. The activities in the schedule must be properly executed, resulting in certain performance. This performance is recorded in performance contracts as well.

This paper enriches the known model of asset management from economics and finance by reflecting on an approach from ICT, military, naval, aerospace, or oil-andgas industries. A way to organize the procurement process including performance-based requirements and performance validation is according to the V-model (Figure 2 ). The $\mathrm{V}$-model approach is often used in industrial engineering domain, especially in projects with a strict Quality Assurance (QA) protocol.

This paper adopts the existing model and connects it with the three levels of decision regarding procurement strategy. There are three possible tender procedures, from engineering-and-build, to design-and-build, towards turnkey. Within all process stages, the proposed design or engineering solutions by the contractor can be interactively validated against the performance requirements. When the client aims to procure a project based on user's performance requirements and by allowing the contractor to propose design and construction solutions, option 1 (i.e., turn-key) can be selected. When the client establishes the principal design, but wishes to allow the contractor to elaborate the design and propose (innovative) materials and construction techniques, option 2 (i.e., design-and-build) is the most suitable. When the client has elaborated the design and wishes to ask the contractor to carry out the detailed engineering and construction, option 3 (i.e., engineering and build) can be applied.

3.1.2. Practice. The concept of performance-based procurement has largely been introduced in the EU. However, the adoption of this concept in the daily practice is still limited. The analysis result from the recent survey in the Trans-IND project shows the following facts [14].

In terms of policy, the importance of performance-based procurement is high. However, in most EU countries, the "performance" policy has not yet been endorsed by the existing regulatory framework in the Public Procurement Law. Neither do the EU directives in the field of public and utilities procurement stipulate how the performancebased procurement and evaluation procedure should be conducted [18]. Since public clients are bound to organize tender procedures of large-scale projects based on the Public Procurement Law, the performance concept has usually been used only by private clients (especially in the building sector) 


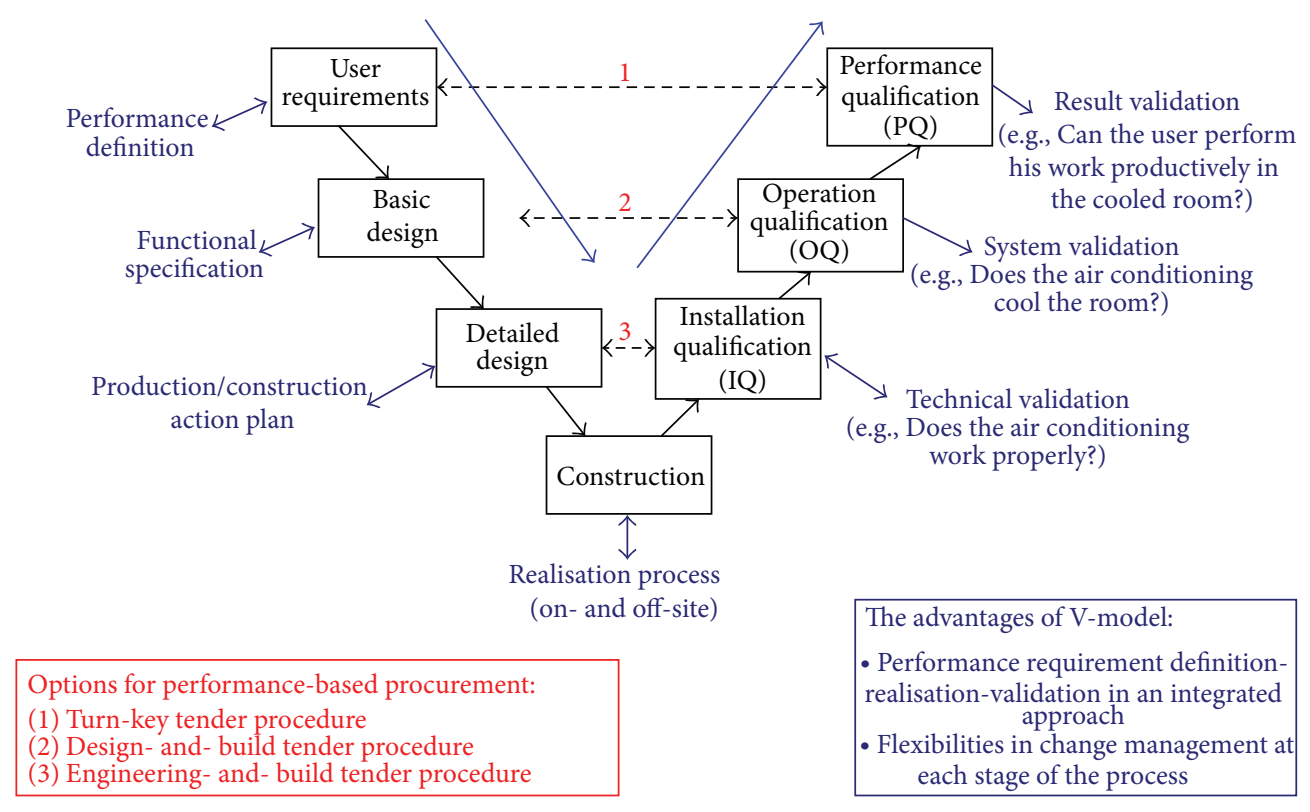

FIGURE 2: Proposed V-model for performance-based procurement (adapted from [4]).

but not by the public clients which are dominant in the civil infrastructure sector.

Based on the applicable Public Procurement Law, both the traditional tendering method (design-bid-build) and integrated tendering method (design-and-build) are used in the EU countries. Although the traditional tendering method is still dominant, design-and-build tenders are growing in number and size. Price-particularly "lowest price" - is still the most important aspect of tender yet other performance aspects have been included in tendering according to "Most Economically Advantageous Tender (MEAT)" [6].

In Poland, an exemplary catalogue of tender evaluation criteria has been included in article. 91 item 2 of the Act PPL. These are quality, functionality, use of the best available technologies within the scope of impact on natural environment, exploitation costs; or impact of the manner of performing the contract on the labor market in place of performing the contract. Occasionally the criterion of warranty time is taken into account. In 2007, the Polish authorities introduced the pilot procedures of design-build (DB) model. Currently, the DB model is gaining on popularity and becomes more widely applied for public procurement in civil infrastructure.

According to the law in Italy, public procurements are based on two main assignment criteria: "lowest price" and "the most economically advantageous offer." The first implies that public administration must define the order characteristics in the call and participants must specify only the price. According to the Public Contacts Code Article 83, the performance requirements considered for evaluating the most economically advantageous offer are price, quality, technical merit, aesthetical and functional characteristics, environmental characteristics and energy saving, uses and maintenance costs, profitability, after sales service, technical assistance, deliverable date and terms, effort in terms of spare parts, and assurance of procurement. In case of a concession contract, the contract duration, management conditions, and payment criteria are agreed with the end users.

Initiatives or actions have been taken in The Netherlands to move from "lowest-price tender" towards "performancebased tender." PIANOo (http://www.pianoo.nl/), the Dutch Public Procurement Expertise Centre, was set up in 2005 to professionalize procurement and tendering in all government departments, with a view of improving efficiency and compliance with the rules. Regarding performance-based procurement, PIANOo prioritizes the Sustainable Procurement by stimulating the market for sustainable products and jointly developing criteria and practical instruments to implement Sustainable Procurement within the organization. Other performance-related goals of the professional procurement/tendering include lower failure costs, more interaction with the market (supply chain integration and market knowledge), competition, innovation (sustainability); and value for taxpayers' money.

In Sweden, the problems emanating from the use of relative evaluation models for MEAT procurement were well illustrated in a recent court ruling by the Gothenburg Administrative Court of Appeal [19]. It could be inferred that relative evaluation models do not violate the procurement law but that the legality of such model must be assessed in each individual case.

\subsection{Value-Chain Integration from the Contractor's Perspective}

3.2.1. Concept. Within the global view of industrialized and automated production and construction processes, 
technology leading construction companies are using technologies such as robotics, automated machinery and assembly systems, sensors, virtual reality, 3D laser scanning, and Intelligent Technology Infrastructure for an integrated management of the production lines. On the other hand, the traditional manufacturing sector is progressively facing a change towards more complex and personalized products, shorter lifecycles and strong commercial pressure from the global market. It is absolutely necessary for companies to adapt to this trend in order to stay competitive while maintaining and improving the quality of life of the workers. This can only be achieved by optimizing processes, boosting RTD and innovation, and obtaining the highest performance from their most valuable asset: the knowledge of their products.

Initial approaches to the adoption of product configurations and processes to engineering and manufacturing companies have been accomplished in the research projects, that is, EU FP6 SWOP [20] and EU FP6 ManuBuild [21]. The efficient use of knowledge in product engineering, development processes, manufacturing, and assembly is proposed as the key factor to achieve this. This has facilitated a shift from paper-based design processes towards fast and efficient knowledge processes, as well as a shift from resourcebased towards knowledge-based manufacturing within the construction sector. The products and processes can be customized according to the geographical, architectural, material, costs, and other restrictions.

Within the Trans-IND research project, comakership (i.e., long-term collaboration with the other partners in the supply chain, like material suppliers, design specialists, maintenance specialist) has been identified as a strategy for value-chain integration from the contractor's perspective [22]. Comakership is considered very important, especially because it enables the involved parties to negotiate and achieve lower prices of the materials/components/services for a larger scale/volume/number of projects. Another significant issue is the quality of the cooperation and trust, which will become much better if one knows the partners well and has collaborated with them before. In this way it is easier to anticipate potential problems/risks that may occur [23].

The initiatives and actions taken to move from "oneoff collaboration in a single project" towards "long-term collaboration for serial projects based on industrialization approach" depend very much on the type of the contract/project. Similarly, the selected collaboration strategy for the comakership (e.g., preferred partners/suppliers- and product- and based consortium- and joint venture- and client and Contractor alliance) depends on the size and characteristics of the contract. In a large-scale project in general, projectbased consortium is the most known form of comakership. In projects with a smaller scale, a consortium with preferred partners/suppliers is set up. When specific experience and qualifications of the partners are important, a consortium with a small number of specialized players is established for a number of similar projects. Sometimes it is inevitable to setup a project consortium due to the large size of the required investment. A frequently used action is the establishment of a framework agreement, for instance between the main contractor and the suppliers of material or the subcontractors, as well as by involving an investor or a financer.

3.2.2. Practice. The result from the recent surveys among the construction and manufacturing companies associated with the Trans-IND project can be summarized as follows (TransIND, D9.4).

A small number of comakerships have been observed between the manufacturing companies and the suppliers or specialized design engineers. An example from The Netherlands regards the comakership around Fibercore Europe and Lightweight Structures BV (LSBV), which are the only companies in The Netherlands that produce FRP bridges using infusion techniques. The first example involves Fibercore and Smit Kunststoffen. Fibercore is the leading company in NL with more than 50 bridges made using this technique, including several traffic bridges with the highest load level. The comaker company, Smit Kunststoffen, produces finishing panels for viaducts which are developed by Fibercore. Another company, Haasnoot Bruggen, produces the decks for bridges (thus, not the whole bridges) with pultruded profiles from Denmark. In the past, Haasnoot collaborated with Fibercore for infusion bridges. The second example involves LSBV and Takke Breukelen. LSBV has made one or two such bridges in the city of Utrecht with infusion and hybrid infusion-pultrusion technology. The comaker company, Takke Breukelen, currently collaborates with LSBV, most likely in the production of decks with pultrusion profiles.

In the Polish construction sector, the most common forms of comakership are (1) preferred suppliers and (2) project-based consortia. The difference between these models regards the responsibility sharing. By participating in the contract only as a subcontractor (supplier), a company is not responsible to the client but only to the general contractor. Each member of any project-based consortium is responsible to the public client. Until 2009, the Polish Public Procurement Law favored the formation of projectbased consortia, because its provisions clearly required that any bidder (a single company or consortium) must have the experience and capacity necessary to perform all the required works. This situation has changed since the amendment of the Polish Public Procurement Law of 2009, which introduced the provision that a bidder does not need to have all the necessary experience and can be supported by other entities without the need to form the consortium.

The most important selection criteria used to select the partners are based on the track records, especially regarding the quality of works delivered, the punctuality of the process (projects delivered on-time), and the price. In other words, the key criterion is the ability of the contractors to provide services necessary to fulfill the contract. When the project is very complex and the general contractor (or consortium leader) is technically unable to provide all necessary services, then a very important criterion is the subcontractor's experience and quality of services (i.e., a subcontractor provides the so-called complementary services). 


\section{Conclusions}

Value-chain integration for FRP bridges through asset management business model is aligned with the implementation of integrated procurement. Procurement is a generic term embracing all those activities undertaken by a client seeking to bring about the construction or refurbishment of a building. The project strategy will necessitate making an analysis of the situation, making a choice from the procurement options and then devising a method of implementing that choice, using well-established rules and procedures. Identifying and dealing appropriately with risk at the outset is an integral part of any project strategy.

Asset management is especially relevant in relation with the integrated procurement methods of DBFM and DBM. The implications of asset management can be concluded as follows.

(1) Design, build, finance and Maintain (DBFM): In a normal market situation, the private parties are usually able to arrange project financing faster than the public parties. The business case is reliable due to external financing. The complex financial arrangement requires much effort and special legal and finance expertise.

(2) Design, build and Maintain (DBM): maintenance cost can be anticipated in design and becomes the responsibility of the same contractor. An adequate method to predict and calculate risks due to external uncertainties (political and market changes) is needed.

The implications of research in the Trans-IND and PANTURA projects as presented in this paper to theoretical studies can be concluded as follows. Up till now, the dominant amount of research on asset management in the civil infrastructure sector has mainly addressed two main knowledge areas: (1) the adoption of the asset management principles from economics and finance into construction and (2) information management and decision-making instruments to handle object and area data of civil infrastructure assets. This paper has shown how a leveraging paradigm such as asset management should and can also be associated with innovations in construction materials and structural designs. The development and market growth of FRP as a relatively new structural material in the civil infrastructure sector present a crucial challenge to how asset management concepts are to consider the value chain of the FRP materials as well as the FRP-based component production and bridge preconstruction processes. The components of a prefabricated FRP bridge need to be available over the lifespan of the bridge for maintenance and replacements. In this sense, longterm procurement strategy based on asset management needs to consider not only agreement with the main contractor, but also the downstream value chain of components and materials with the FRP suppliers and manufacturers. Furthermore, asset management related to FRP bridges also needs to consider new possibilities in reallocation, reuse and recycling of an FRP bridge or its components.

The implications of the research to industry can be concluded as follows. The three primary drives behind the use of asset management in the civil infrastructure sector are (1) better functioning of the infrastructure as a network (e.g., better overall mobility in the region instead of the sole quality of individual roads); (2) optimal lifecycle sustainability of the infrastructure assets; and (3) the lowest lifecycle cost refers to the cost of constructing, rehabilitating, repairing or replacing the infrastructure assets. FRP bridges directly meet all of these drives, with particularly high competitiveness regarding the lifecycle sustainability and cost. This paper (re)emphasizes this aspect, especially by connecting the theoretical discussions with the experience from recent projects in Europe, supported by the outcomes from the market study in several European countries. Moreover, as both Trans-IND and PANTURA projects are sustained by large industrial consortia, the most important market players have been represented and committed in creating a wider market impact of FRP bridges. This paper presents several practical solutions for these market players regarding the procurement strategy that is needed to facilitate the wider implementation of asset management.

Aligned with the abovementioned conclusions, the most urgent recommendation is on resolving crucial challenges that hinder the broad implementation of performance-based procurement, which are the high tender cost and the lack of objective evaluation standards. This barrier is common to all countries. Therefore, the value-chain aspects should be included next to the technical aspects in the current effort to establish the European and international standards for FRP bridges.

In order to create a wider impact at the $\mathrm{EU}$ or international level, common key performance indicators (KPIs) are needed to measure and benchmark the achievements of FRP based civil infrastructure projects through asset management approach. Standard guidelines are important to provide (public) clients with solid references and valid justifications when determining their procurement strategies to adopt the FRP materials and construction techniques. In the EU context, In the EU, further research should clarify which elements of the KPIs can be standardised, and subsequently classify them either as EU-generic or local/countryspecific, taking into account the similarities and differences of procurement frameworks in the EU in the different member states.

\section{Acknowledgments}

This paper is written and presented as a part of research and knowledge dissemination activities of the EU FP7 collaborative research projects Trans-IND (http://www.transind.eu/) and PANTURA (http://www.pantura-project.eu/). The author is a principal investigator in the work package on business models for FRP bridges. 


\section{References}

[1] Trans-IND D9.4, "Innovative business model for transport infrastructure projects," Project Report, 2012.

[2] PANTURA D5.8, "Model for management of strengthening and repair for bridges," Project Report, 2012.

[3] R. Vrijhoef and H. A. J. de Ridder, "Living building concept: a new approach to value delivery in the built environment," in Proceedings of Portugal SB07 Conference, L. Braganca, M. Pinheiro, S. Jalali, and R. Mateus, Eds., IOS Press, Amsterdam, The Netherlands, 2007.

[4] K. Forsberg, H. Mooz, and H. Cotterman, Visualizing Project Management: Models and Frameworks for Mastering Complex Systems, John Wiley \& Sons, Hoboken, NJ, USA, 2005.

[5] European Parliament, Directive 2004/18/EC of the European Parliament and of the Council of 31 March 2004 on the Coordination of Procedures for the Award of Public Works Contracts, Public Supply Contracts and Public Service Contracts, European Parliament, Brussels, Belgium, 2004.

[6] R. Sebastian, C. Claeson-Jonsson, and R. Di Giulio, "Performance-based procurement for low-disturbance bridge constructionprojects," Construction Innovation: Information, Process, Management. Forthcoming.

[7] BSI, Asset Management: Guidelines for the Application of PAS 551, British Standard Institution, London, UK, 2008.

[8] BSI, Asset Management: Specification for the Optimized Management of Physical Infrastructure Assets, British Standard Institution, London, UK, 2008.

[9] D. J. D. Vanier, "Why industry needs asset management tools," Journal of Computing in Civil Engineering, vol. 15, no. 1, pp. 3543, 2001.

[10] M. R. Halfawy, "Integration of municipal infrastructure asset management processes: challenges and solutions," Journal of Computing in Civil Engineering, vol. 22, no. 3, pp. 216-229, 2008.

[11] A. Erridge and G. Callender, "Introduction to the special issue on public procurement," Journal of Purchasing and Supply Management, vol. 11, no. 5-6, pp. 209-211, 2005.

[12] Joint Contract Tribunal JCT, “Procurement," April 2013, http://www.jctltd.co.uk/procurement.aspx.

[13] S. Spatari and A. E. Aktan, "Asset management in civil engineering," Structure and Infrastructure Engineering: Maintenance, Management, Life-Cycle Design and Performance, vol. 9, no. 4, pp. 295-296, 2013.

[14] Trans-IND D9.2, "Current business models for transport infrastructure projects," Project Report, 2011.

[15] R. Sebastian and K. A. van Gelderen, "Developing a model to support client's decision-making process on integrated contracts," in Proceedings of WCPM International Conference, Delft, The Netherlands, October 2007.

[16] M. Dreschler, Fair competition [Ph.D. dissertation], Delft University of Technology, 2009.

[17] T. P. van Houten and L. L. Zhang, "Managing assets in the infrastructure sector," International Journal of Engineering Business Management, vol. 2, no. 2, pp. 55-60, 2010.

[18] T. Bianchi and V. Guidi, Eds., The Comparative Survey on the National Public Procurement Systems across the PPN, Authority for the Supervision of Public Contracts/Department for the Coordination of European Union Policies, Rome, Italy, 2010.

[19] J. Lavér and O. Larsberger, "The Art of Identifying "The Most Economically Advantageous Tender"-The Use of Relative Evaluation Models in Public and Utilities Procure- ment," April 2012, http://www.whoswholegal.com/news/features/article/29137/the-art-identifying-the-economicallyadvantageous-tender-use-relative-evaluation-models-publicutilities-procurement/.

[20] M. Bohms, P. Bonsma, M. Bourdeau, and A. S. Kazi, "Semantic product modelling and configuration: challenges and opportunities," Journal of Information Technology in Construction, vol. 14, pp. 507-525, 2009.

[21] A. S. Kazi, M. Hannus, S. Boudjabeur, and A. Malone, Eds., Open Building Manufacturing: Core Concepts and Industrial Requirements, VTT, Espoo, Finland, 2007.

[22] R. Sebastian, "Practical applications of asset management and co-makership business models for FRP bridges," in Proceedings of the 1st Conference on Civil Engineering Infrastructure Based on Polymer Composites (CECOM '12), Krakow, Poland, November 2012.

[23] J. S. J. Koolwijk, "Risks shared and allocated by construction clients and contractors in Dutch (hybrid) project alliances," in Proceedings of CIB World International Conference, Salford, UK, 2010. 

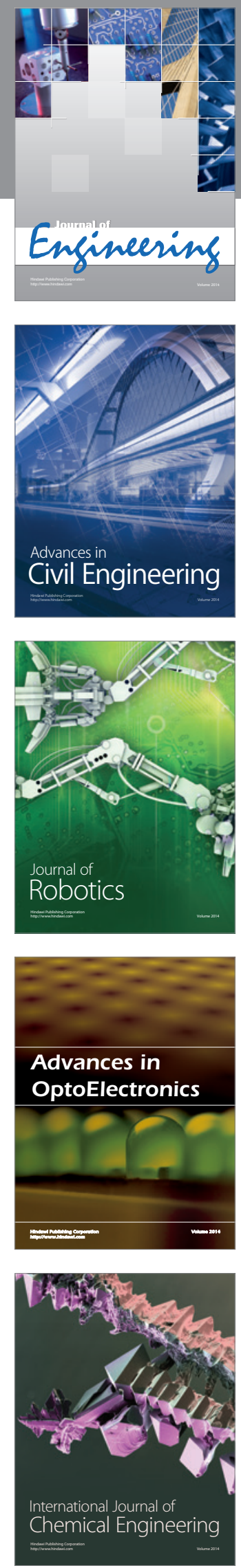

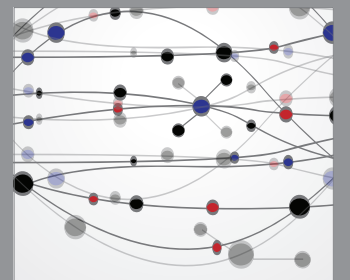

The Scientific World Journal
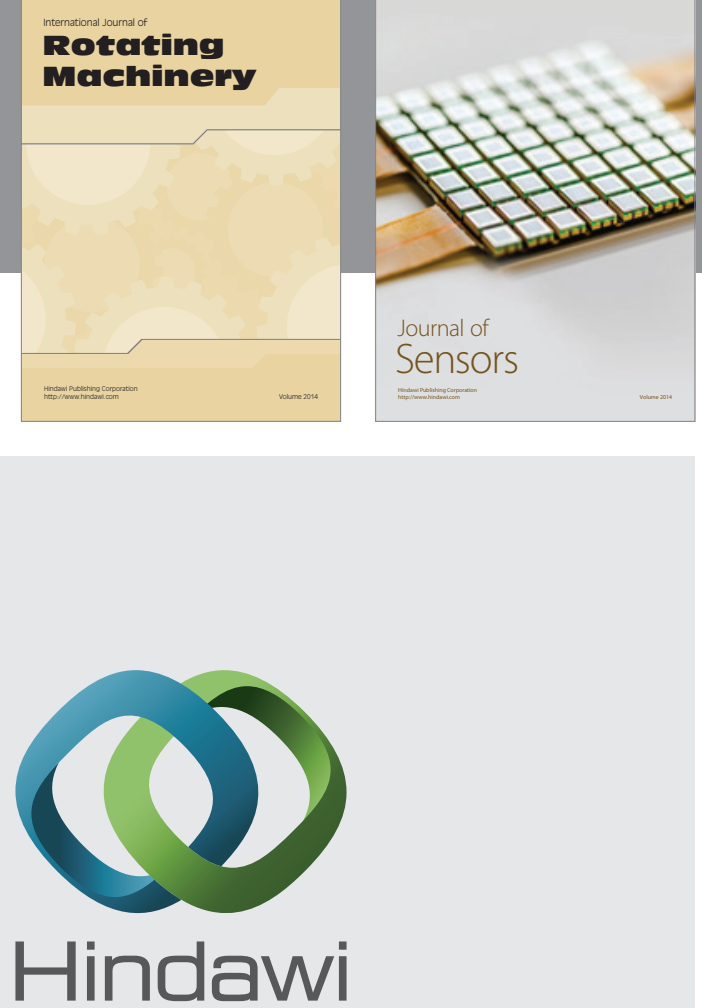

Submit your manuscripts at http://www.hindawi.com
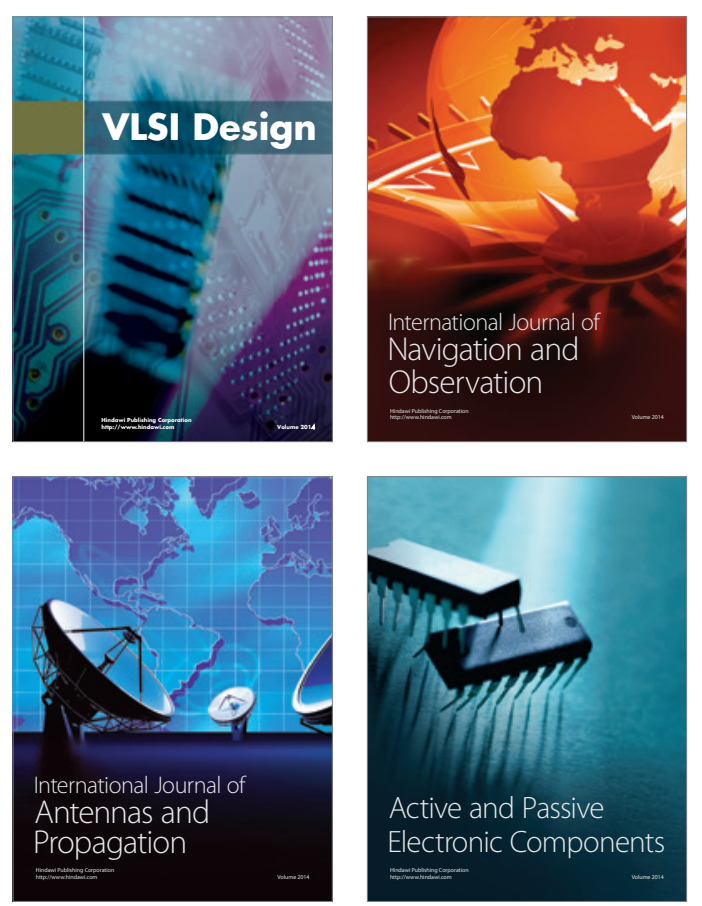
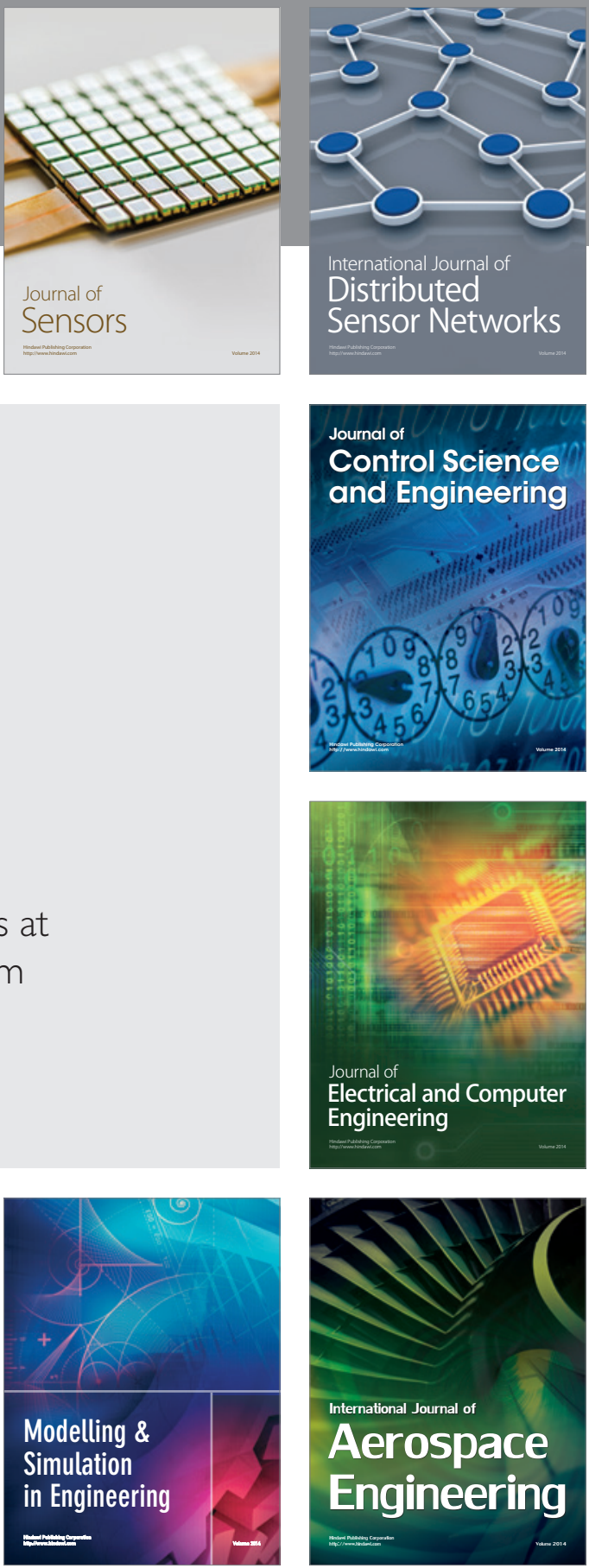

Journal of

Control Science

and Engineering
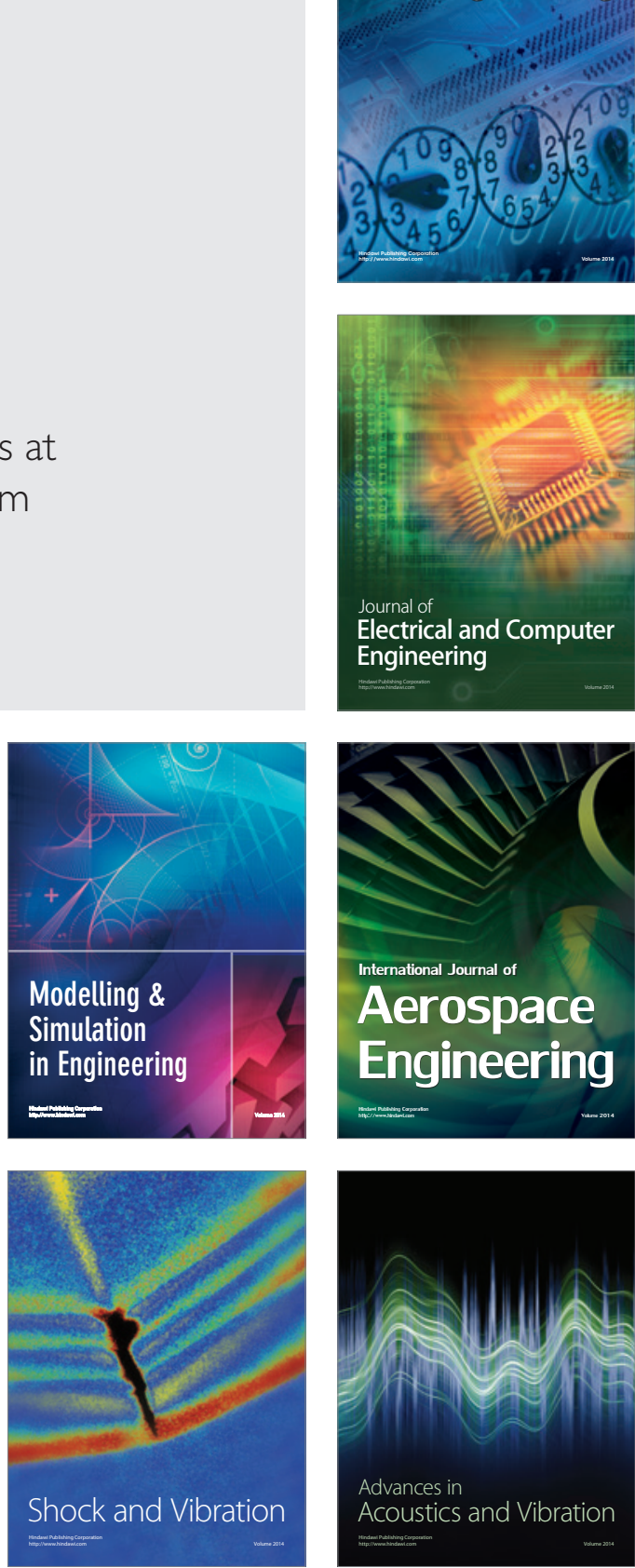